\title{
Impact of Ganges-Brahmaputra interannual discharge variations on Bay of Bengal salinity and temperature during 1992-1999 period
}

\author{
Fabien Durand ${ }^{1, *}$, Fabrice Papa ${ }^{2,3}$, Atiqur Rahman ${ }^{2}$ and Sujit Kumar Bala ${ }^{4}$ \\ ${ }^{1}$ LEGOS, IRD, Nouméa, New-Caledonia. \\ ${ }^{2}$ NOAA-CREST, New York, NY, USA. \\ ${ }^{3}$ LEGOS, IRD, Toulouse, France. \\ ${ }^{4}$ Bangladesh University of Engineering and Technology, Dhaka, Bangladesh. \\ *Corresponding author.e-mail: fabien.durand@ird.fr
}

\begin{abstract}
This study investigates the impact of monthly Ganges-Brahmaputra river discharge variations on Bay of Bengal salinity and temperature during the period 1992-1999. The Ganges-Brahmaputra river discharge is characterized by a well-defined seasonal cycle with strong interannual variations. The highest/lowest yearly peak discharge occurs in summer 1998/summer 1992, with 1998 value amounting to twice that of 1992. This river discharge is then used to force an ocean general circulation model. Our main result is that the impact of these rivers on the variability of Bay of Bengal sea surface salinity is strong in the northern part, with excess run-off forcing fresh anomalies, and vice versa. Most of the years, the influence of the interannual variability of river discharge on the Bay salinity does not extend south of $\sim 10^{\circ} \mathrm{N}$. This stands in contrast with the available observations and is probably linked to the relatively coarse resolution of our model. However, the extreme discharge anomaly of 1998 is exported through the southern boundary of the Bay and penetrates the south-eastern Arabian Sea a few months after the discharge peak. In response to the discharge anomalies, the model simulates significant mixed-layer temperature anomalies in the northern Bay of Bengal. This has the potential to influence the climate of the area. From our conclusions, it appears necessary to use a numerical model with higher resolution (both on the horizontal and vertical) to quantitatively investigate the upper Bay of Bengal salinity structure.
\end{abstract}

\section{Introduction}

The Bay of Bengal (henceforth BoB) in the northern Indian Ocean plays a central role in the tropical climate system. Its sea surface temperatures (SSTs) are consistently hovering around $28^{\circ} \mathrm{C}$, a threshold value considered as necessary for the development of deep atmospheric convection (Gadgil et al 1984). The intensity of airsea coupling over the BoB is supposedly favoured by a sharp ocean salinity stratification, resulting from the excess freshwater supply (coming from both rainfall and river run-off) over evaporation (Vinayachandran et al 2002). If the spatiotemporal features of precipitation over the BoB are nowadays well documented (e.g., Hoyos and Webster 2007), much less is known about the contribution of continental run-off from surrounding rivers on salinity variability. It is suggested that continental run-off accounts for about $60 \%$ of the total freshwater received by the BoB (Sengupta et al 2006), of which $40 \%$ is supplied by the Ganges

Keywords. Bay of Bengal; salinity; run-off; Ganges; Brahmaputra; oceanography; modelling. 

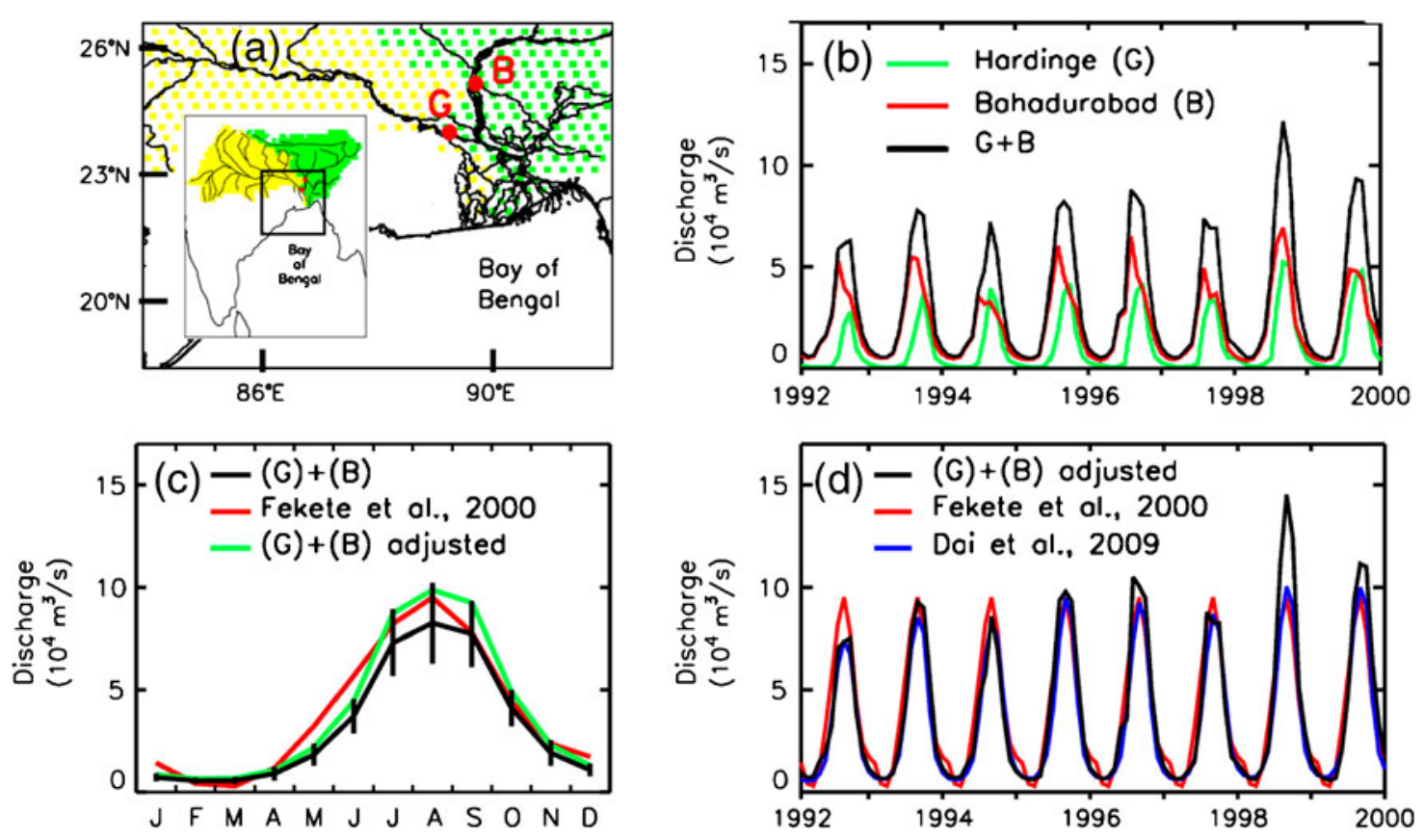

Figure 1. (a) Location of the two stations used in the present study: Hardinge is on the Ganges ((G), watershed shaded in yellow), Bahadurabad is on the Brahmaputra ((B), watershed in green). (b) 1992-1999 evolution of the discharge observed at the two stations, and their sum. (c) The black line is the monthly climatology of the sum of the two discharges $(\mathrm{G})$ and (B) based on the raw time series shown in (b); the vertical bars show the monthly evolution of its interannual variability, defined by \pm 1 standard deviation; the red line is the monthly climatology of the Ganges and Brahmaputra rivers discharge estimated by Fekete et al (2000); the green line is the same as the black line, after scaling by $121 \%$ (see the text for details). (d) 1992-1999 evolution of adjusted discharge (black line), superimposed on the repeated climatology of Fekete et al (2000) (red line). The Ganges-Brahmaputra discharge estimate from Dai et al (2009) is also shown in blue.

(hereafter $\mathrm{G}$ )-Brahmaputra (hereafter B) river system (figure 1a). (G)-(B) is indeed the third largest freshwater outlet to the world ocean, with only the Amazon and the Congo surpassing the combined discharge of these two rivers. However, up to now, only coarse estimates of river run-off into the BoB based on seasonal climatologies of hydrological models have been available (e.g., Dai and Trenberth 2002, and references therein). This has severely limited our ability to fully understand the climatic impacts of $\mathrm{BoB}$ run-off variations in the region, particularly at interannual timescales (Vinayachandran and Nanjundiah 2009). Recently, Dai et al (2009, henceforth D09) produced a global multi-decadal estimate of the evolution of the continental discharge to the world's oceans, which includes estimates of the $(\mathrm{G})-(\mathrm{B})$ river discharge into the BoB from 1948 to 2004. This product, however, remains limited to yearly timescales, and does not resolve the intra-annual signals. Another specific limitation of this product for studies over the $\mathrm{BoB}$ is that their estimate of $(\mathrm{G})$ discharge relies on observations limited to the pre-1996 era. The subsequent years consist of synthetic discharge data, constructed from numerical model outputs.

Hydrological observations in the $(\mathrm{G})-(\mathrm{B})$ rivers across Bangladesh have been carried out by the Bangladesh Water Development Board since the early 1940's [http://www.bwdb.gov.bd/]. In general, public access to latest river discharge observations in the area is restricted but daily in situ discharge observations for these two rivers over the 1992-1999 period have been made available to us (Papa et al 2010) as well as to Jian et al (2009). The pluri-annual time span of the dataset is unprecedented in this part of the world.

In this study, we first briefly summarize the characteristics of the dataset, focusing on the period 1992-1999 and concentrating on what is relevant for the oceanic freshwater budget. We then use the river discharge observations to force an ocean general circulation model (OGCM), in order to assess its impact on the interannual variability of BoB sea surface salinity (henceforth SSS) and upper ocean temperature.

\section{Data and methods}

\subsection{River discharge dataset}

We have access for the present study to discharge data derived from water levels measured at the two basin outlet stations in Bangladesh before their confluence (figure 1a): the Hardinge Bridge station $\left(24.07^{\circ} \mathrm{N} ; 89.03^{\circ} \mathrm{E}\right)$ on $(\mathrm{G})$ and the Bahadurabad 
station $\left(25.15^{\circ} \mathrm{N} ; 89.70^{\circ} \mathrm{E}\right)$ on $(\mathrm{B})$. The accuracy of these discharge measurements is not known since it is extremely difficult to measure the depth and velocities, and consequently the discharge, of wide and mighty rivers like $(\mathrm{G})$ and $(\mathrm{B})$ (Chowdhury and Ward 2004); however typical accuracy of river discharge measurements is assumed to be in the range of $10 \%$ to $20 \%$ (Fekete et al 2000).

In the following, we will consider the monthly mean discharge values for $(\mathrm{G})$ and $(\mathrm{B})$ calculated from their daily discharge records over the period 1992-1999. A detailed description of 50-year daily discharge for both rivers and their variations at intra-seasonal and seasonal time-scales is given in Jian et al (2009). The complete time series are displayed in figure 1(b). Both river discharges show a prominent seasonal cycle, superimposed on a rather strong interannual variability that takes the form of large year-to-year modulation of the magnitude of their seasonal peak flow. Being the relevant parameter for ocean studies, figure 1(b) also shows the total river discharge of the $(G)-(B)$ system (obtained by summing the two individual discharges). As expected, the resulting total discharge (G)-(B) (mean \pm standard deviation of $32250 \pm$ $\left.29850 \mathrm{~m}^{3} \cdot \mathrm{s}^{-1}\right)$ also shows a prominent seasonality with a maximum $\left(83750 \pm 17920 \mathrm{~m}^{3} \cdot \mathrm{s}^{-1}\right)$ occurring usually in August, but with large year-to-year variations in the magnitude and, to some extent, in the timing of the peak. For instance in 1992, the combination of a relatively low peak flow for $(G)$ and a lag of two months between the two maximum river discharges (July for (B), September for $(G)$ for this year) results in the lowest yearly peak of the total discharge record in September with $62990 \mathrm{~m}^{3} \cdot \mathrm{s}^{-1}$. On the other hand, the largest yearly peak of (G)-(B), occurring in August and September 1998 with $122,100 \mathrm{~m}^{3} \cdot \mathrm{s}^{-1}$, is associated with the simultaneous occurrence of discharge maxima in both rivers in late August and early September.

In the remainder of this paper, our objective is to investigate the impact of interannual variabil- ity of (G)-(B) discharge on BoB SSS. To do so, the monthly river discharge $(\mathrm{G})-(\mathrm{B})$ over the time period 1992-1999 is used to force an OGCM of the tropical Indian Ocean.

\subsection{The $O G C M$}

Our OGCM is the same as the one used in Durand et al (2007; henceforth D07). It uses NEMO model (Madec 2008). It solves the primitive equations on a grid with $0.5^{\circ}$ horizontal resolution, on 31 vertical z-levels, with $10 \mathrm{~m}$ vertical resolution in the upper $120 \mathrm{~m}$. The vertical physics is based on a prognostic equation for the turbulent kinetic energy (Blanke and Delecluse 1993). Detailed description of the model set-up can be found in D07, including an extensive validation of the simulated seasonal climatology of SSS, with a focus on the southwestern Bay of Bengal and southeastern Arabian Sea. In particular, it was tuned to simulate properly the inflow of northern BoB fresh waters in the south-western BoB, past Sri Lanka and into the southeastern Arabian Sea occuring during winter. The present study uses multi-year integration of this model forced by interannually varying fluxes of momentum, heat, precipitation and evaporation over January 1992-December 1999. We followed the same strategy as D07 as regards to the forcing products. We used ERS-1-2 scatterometer wind stress (at $1^{\circ} \times 7$ days resolution; Bentamy et al 1996) and CMAP precipitation flux (at 2.5 $\times$ 1 month resolution; Xie and Arkin 1997). The heat and evaporation fluxes are diagnosed from daily NCEP reanalysis (Kalnay et al 1996) air temperature. SSS is not restored to any climatology, except at the boundaries of our domain (along $34^{\circ} \mathrm{S}$ and $\left.115^{\circ} \mathrm{E}\right)$.

Of particular, relevance for the present study is the thickness of the upper mixed layer. It is indeed this layer that receives and transports the continental freshwater. In order to validate the mixed layer depth (MLD) simulated by the model, figure 2

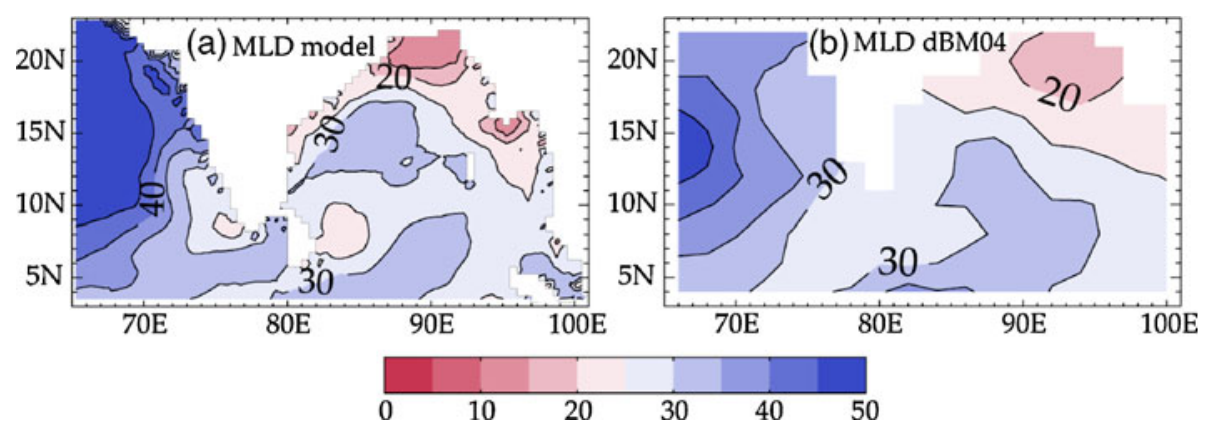

Figure 2. (a) Long-term mean mixed layer depth (MLD, defined as the depth at which seawater density exceeds sea surface density by a quantity equivalent to a $0.2^{\circ} \mathrm{C}$ temperature drop) simulated by the model. Isocontours are every $5 \mathrm{~m}$. Red shades indicate MLDs thinner than $25 \mathrm{~m}$. (b) Same as (a), from the observations of dBM04. 
presents a comparison with the observed climatology of de Boyer Montégut et al (2004; noted as dBM04 in the following). Despite its fairly coarse vertical resolution of $10 \mathrm{~m}$, the model simulates a shallow MLD throughout the BoB, with values ranging from 20 to $30 \mathrm{~m}$. This stands in very good agreement with the observations of dBM04. The model also satisfactorily reproduces the pattern of extremely shallow MLDs (with values inferior to $25 \mathrm{~m}$ ) hugging the northern boundary of the BoB. The model shows a narrow band of shallow MLD extending towards the southwest along the western boundary of the Bay, as well as a localized pattern off the mouths of the Irrawaddy centred on $95^{\circ} \mathrm{E}$ and $15^{\circ} \mathrm{N}$. These two patterns are not resolved by the observations used by $\mathrm{dBM} 04$, and hence are hard to validate.

It is also important to validate the surface circulation simulated by the model. The East India Coastal Current (EICC) lies at the western boundary of the BoB. It plays a central role in the export of Bay of Bengal fresh water mass into the Equatorial Ocean and Arabian Sea (Shetye et al 1996; Shankar et al 2002; D07). Figure 3 shows the seasonal climatology of EICC surface velocity simulated by the model along the western boundary of BoB. It is seen that the simulated seasonal EICC presents a well-organized structure in space and time. In October, the EICC flows equatorward all along its path, with values ranging from 0.2 to $0.4 \mathrm{~m} \cdot \mathrm{s}^{-1}$. It picks up in November to reach maximum values of $0.8 \mathrm{~m} \cdot \mathrm{s}^{-1}$ at $12^{\circ} \mathrm{N}$ in late November.

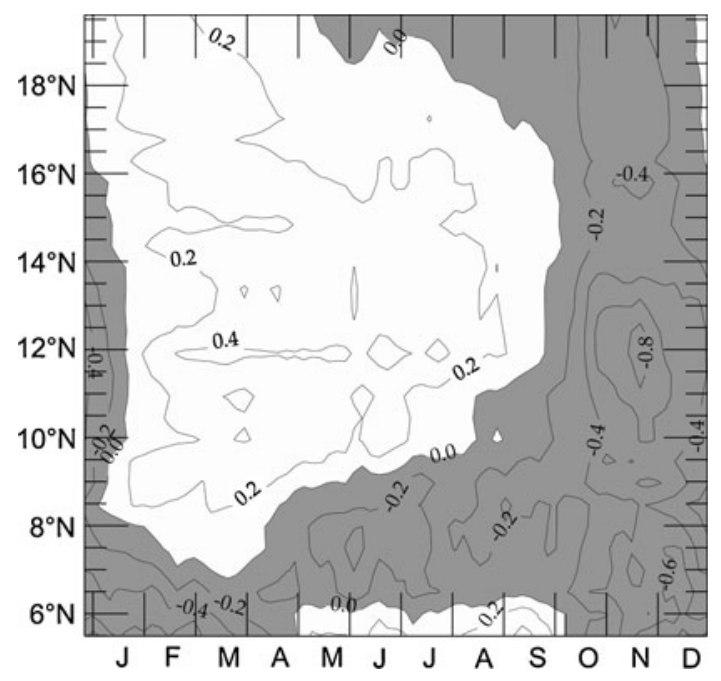

Figure 3. Seasonal climatology of EICC surface velocity as a function of latitude along Sri Lankan $\left(6^{\circ}-10^{\circ} \mathrm{N}\right)$ and Indian $\left(10^{\circ}-20^{\circ} \mathrm{N}\right)$ east coasts simulated by the model. The model surface currents were projected in the alongshore direction. Contour interval is $0.2 \mathrm{~m} \mathrm{~s}^{-1}$. Positive values indicate eastward and northward current. Negative values are shaded.
It then decays and reverses everywhere north of $8^{\circ} \mathrm{N}$ by February. South of $7^{\circ} \mathrm{N}$, on the southeast coast of Sri Lanka, the timing is somewhat different: the current remains southwestward until April. The current reverses in May to flow poleward. In August, the northward flowing EICC decays in the north, then vanishes by September. In October, it starts flowing equatorward at all latitudes. This evolution stands in broad agreement with the ship drifts of Mariano et al (1995) (see Durand et al 2009, their figure 2). At $16^{\circ} \mathrm{N}$, the post-monsoon EICC reversal from poleward to equatorward occurs simultaneously in the model and in the altimetry-derived observations (see Durand et al 2009, their figure 6), and about a month later than in Mariano et al (1995) ship drifts.

The only but major difference in the model setup between D07 and the present study concerns the (G)-(B) run-off forcing flux. In D07, we used the climatology run-off from Fekete et al (2000) (shown in figure 1c, red curve) estimated from a combination of a climate-driven water balance model and observed river discharge information. In the present study, we consider successively two different fluxes: the Fekete et al (2000) climatology and the 1992-1999 monthly time series of $(\mathrm{G})-(\mathrm{B})$ river discharge. However, before being implemented as forcing flux in the model, the new river discharge dataset needs to be adjusted in order to ensure the same long-term average as the estimate from Fekete et al (2000). This exact long-term average consistency between the two estimates ensures that the long-term mean SSS simulated by the model is not impaired as compared to D07. In particular, it ensures that the typical location and magnitude of the SSS front that separates low-salinity Bay of Bengal waters and high-salinity Arabian Sea waters at the southern tip of the Indian subcontinent, as well as its seasonal migrations, are as satisfactory in the present study as they were in D07. As shown in figure $1(\mathrm{c})$, the $(\mathrm{G})-(\mathrm{B})$ dataset present a climatological discharge slightly inferior to the estimate of Fekete et al (2000), especially from May to August. In order to adjust their simulations, Fekete et al (2000) used in situ climatological discharges at Bahadurabad (for 1969-1992) and at Farakka (1949-1974). Farakka is also located on the Ganges River, $\sim 80 \mathrm{~km}$ upstream of Hardinge. Despite their different period of observation and location, these climatologies were found to be almost similar to the ones for (B) and (G) for 1992-1999. As a consequence, it suggests that the difference is due to the fact that $(\mathrm{G})$ and $(\mathrm{B})$ are located quite far upstream of the river delta in Bangladesh. Indeed, unlike Fekete et al (2000) estimate which integrates the entire watersheds (figure 1a), the $(\mathrm{G})-(\mathrm{B})$ does not account for the contribution of local tributaries 
and precipitation downstream of their confluence. In particular, it does not comprise the discharge of the Meghna River (merging with the Ganges and Brahmaputra at $\left.23.25^{\circ} \mathrm{N}\right)$. Some (limited) in situ observations of the Meghna discharge suggest that it yields about $10 \%$ of $(\mathrm{G})-(\mathrm{B})$ discharge at maximum. As a pragmatic way of adjusting our new dataset, we scale it by a constant coefficient. The constraint of identical long-term mean discharge with Fekete et al (2000) yields a coefficient of $121 \%$ which we apply to $(\mathrm{G})-(\mathrm{B})$ discharge to get the socalled ' $(\mathrm{G})+(\mathrm{B})$ adjusted'. Figure 1(c) (green curve) presents its climatology. Though it has the same long-term average as Fekete et al (2000) estimate, it presents slight differences in the seasonal evolution, with in particular a monsoonal rise of the discharge delayed by about one month in our dataset (figure 1c). In the absence of any other independent information, it is hard, however to evaluate which estimate is the most realistic. The same coefficient is then applied to the $(\mathrm{G})-(\mathrm{B})$ interannual monthly time series and the result is displayed in figure 1(d). In order to highlight the interannual variability of ' $(G)+(B)$ adjusted' (standard deviation, noted STD hereafter: $\left.35,700 \mathrm{~m}^{3} \cdot \mathrm{s}^{-1}\right)$, the repeated climatology from Fekete et al (2000) $\left(\mathrm{STD}=31,100 \mathrm{~m}^{3} \cdot \mathrm{s}^{-1}\right)$ is also shown. The STD of their difference is $12,340 \mathrm{~m}^{3} \cdot \mathrm{s}^{-1}$. Figure $1(\mathrm{~d})$ also shows a comparison between ' $(\mathrm{G})+(\mathrm{B})$ adjusted' and the Ganges-Brahmaputra rivers discharge estimate from D09 $\left(\mathrm{STD}=33,900 \mathrm{~m}^{3} \cdot \mathrm{s}^{-1}\right)$. Over 1992-1999, the standard deviation of their difference is $8700 \mathrm{~m}^{3} \cdot \mathrm{s}^{-1}$ and the difference of their mean is about $12 \%$. Over the period 1992-1995, both datasets agree well, the years 1992, 1994 and 1995 being almost identical. In contrast, for the period 1996-1999 the agreement between the two datasets is less strong. In particular, there is a large discrepancy during summer 1998, when the peak value in ' $(\mathrm{G})+(\mathrm{B})$ adjusted' is about $45 \%$ larger than the one from D09. These differences can be explained by the fact that, after 1996, Ganges river discharge estimates from D09 are not based on observations but are constructed discharges based on CLM3 simulations. The moderate correlation of 0.7 for the Ganges between the CLM3 simulations and observed data during 1948-2004 (D09, see their table 1) illustrates the difficulties of CLM3 to reproduce large anomalous events such as the one occurred in 1998.

Interestingly, one can see in figure $1(\mathrm{~d})$ that over the period of record, the interannual anomalies of the river discharge ' $(G)+(B)$ adjusted' typically do not last more than one season.

The first model run forced by the monthly climatology of Fekete et al (2000) run-off repeated over the $1 / 1992-12 / 1999$ period is termed as Control run (henceforth CTRL). The second run using the interannually varying ' $(\mathrm{G})+(\mathrm{B})$ adjusted' discharge (with the discharges of all rivers other than (G) and (B) kept as of Fekete et al 2000) is named as Interannual Run-off run (IR in the following).

\section{Impact on Bay of Bengal SSS}

Figure 4 presents the bimonthly evolution of CTRL SSS over the period May 1992-March 1993. This corresponds to the period of minimum yearly runoff of the record (figure 1). CTRL SSS reveals a build-up of freshwater (salinity inferior to 30; note that we report salinity without units in the practical salinity scale PSS-78) in the northern BoB starting in mid-1992. It corresponds both to the seasonal increase of $(\mathrm{G})-(\mathrm{B})$ discharge (figure 1) and north-eastern BoB rainfall (Hoyos and Webster 2007), picking up as the monsoon advances. A secondary SSS minimum also develops off the mouths of the Irrawaddy, around $15^{\circ} \mathrm{N}$ and $95^{\circ}$ E. From September to November 1992, this freshwater plume progresses southward, hugging both western and eastern boundaries of BoB. On the western boundary, the southward migration is linked with the EICC flowing southward at this time of the year (figure 3). In January 1993, the salinity front defined by the 34 isohaline at the surface, separating the BoB waters from Arabian Sea saltier waters has turned around the southern tip of Sri Lanka and is located in the south-eastern Arabian Sea. This sequence of events realistically reproduces the evolution seen in the observed climatology of Levitus (1998) (see D07, their figure 2). The July pattern, in particular, mimicks the synoptic description of the freshwater tongue achieved by Shetye et al (1991) from a hydrographic cruise carried out all over the western boundary of the BoB in July-August 1989. In order to quantify the impact of the interannual variability of river discharge on the interannual variability of simulated BoB SSS, we computed the difference in SSS between IR and CRTL runs (figure 4, right column). This variable exhibits a well-defined pattern, with an anomaly building up in the northern BoB during summer. The maximal value amounts to 2.10 in July 1992. During September-November, the anomalous pattern propagates towards the south-west along the western boundary of the BoB, following the same pathway as the freshwater tongue discussed in the previous paragraph. Along with their southwestward migration, SSS anomalies decrease in magnitude: by January 1993, typical values of SSS anomaly along the east coast of India and northeast coast of Sri Lanka hardly exceed 0.1. It is interesting to note the south-eastward migration of the 

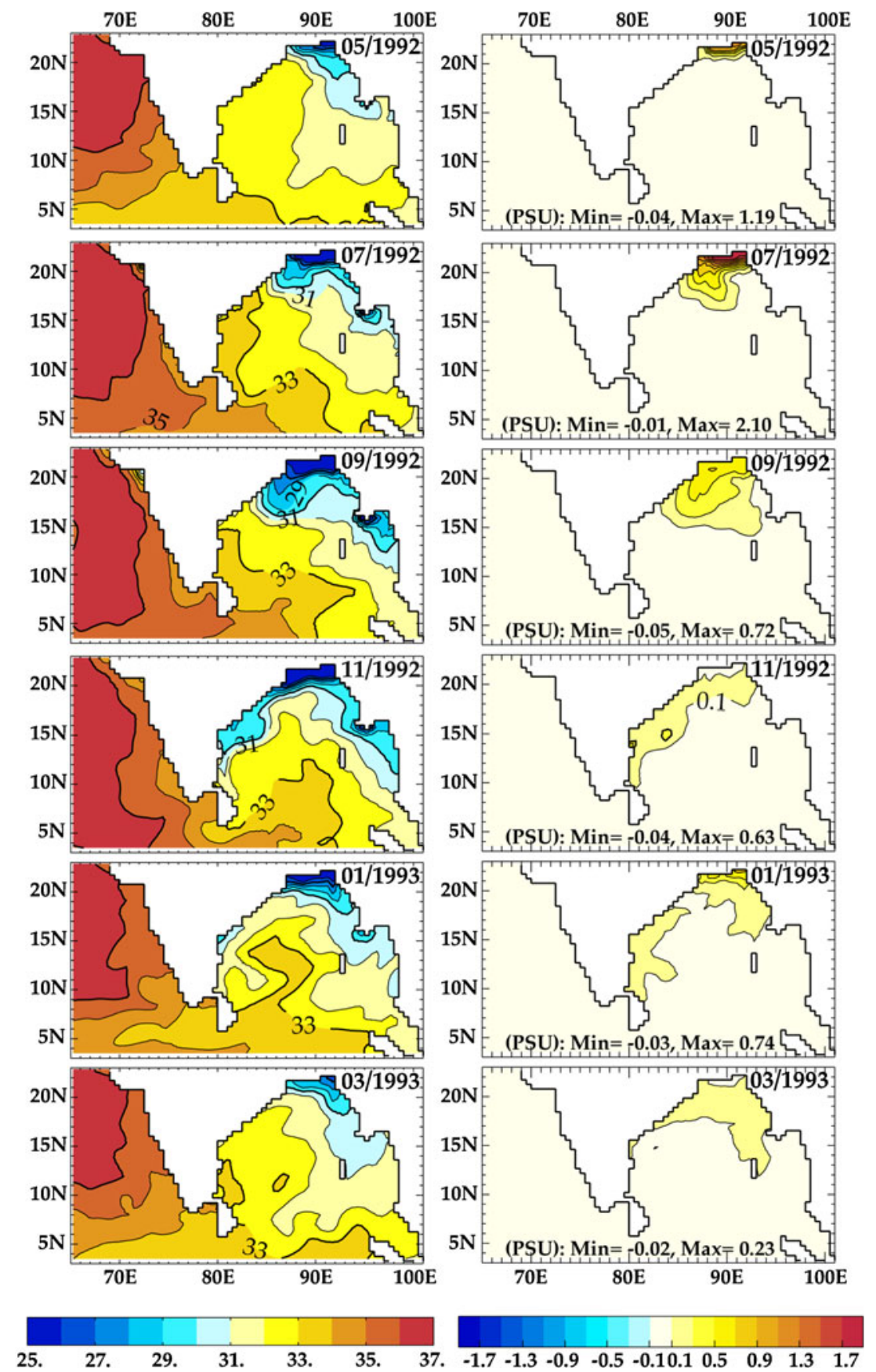

Figure 4. Bi-monthly evolution of SSS from CTRL simulation (left column) and of SSS difference between IR and CTRL simulations (right column), from May 1992 to March 1993. Each snapshot features monthly averages, the corresponding month being indicated. Also indicated on each difference snapshot are the extreme values plotted. Isolines are every 1 on left column and every 0.2 on right column.

anomaly pattern along the north-eastern boundary of the BoB, from November 1992 through March 1993. This is consistent with an advection by the boundary current, north-westerly during this season (not shown; Shankar et al 2002). By March 1993, most of the anomalies have disappeared south of $15^{\circ} \mathrm{N}$. This implies that the mixing processes in the model (vertical and/or horizontal) dissipate the SSS anomalies along their path. Weak anomalies remnant of the anomalous run-off forcing several months earlier remain located in the northern BoB.

We carried out a similar analysis for the period May 1998-March 1999, corresponding to the period of maximum yearly run-off of the record (figure 1). The results are displayed in figure 5 . One can see that the SSS evolution is basically similar to that of 1992-1993, with a build-up of 


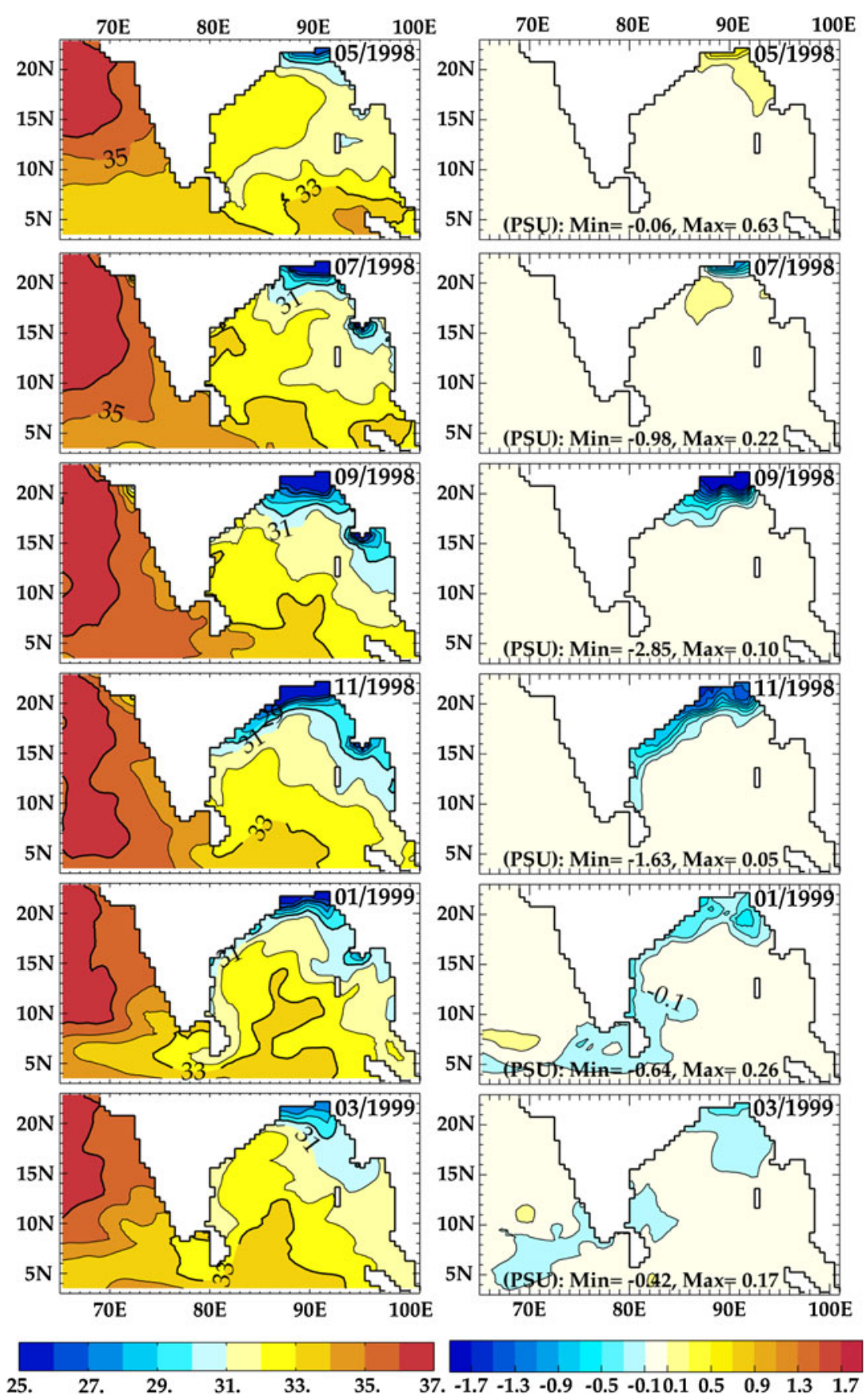

Figure 5. Same as figure 4, from May 1998 to March 1999.

freshwater in the northern BoB in summer and a subsequent southward migration of the plume along both western and eastern boundaries. One difference between the two periods, though, is seen in the fate of the south-westward progression of the freshwater plume: the 33 isohaline does not turn past the southern tip of Sri Lanka in 1992-1993, it penetrates as far as $8^{\circ} \mathrm{N}$ in the southeastern Arabian Sea in early 1999. This echoes to the extremely strong interannual variability of SSS reported from in situ observations in this part of the Indian basin
(Delcroix et al 2005; Gopalakrishna et al 2005). The difference between IR and CTRL SSS in 19981999 (figure 5, right column) also resembles that of 1992-1993, with anomalies of reverse sign. Due to excess G-B discharge subsequently to 1998 monsoon, IR exhibits surface waters excessively fresher than CTRL in the northern BoB from July 1998 onwards. The spatio-temporal evolution of the difference pattern also broadly mirrors that of the freshwater plume, with a south-westward progression from September 1998 to early 1999. However, 
in contrast to $1992-1993$, the difference pattern reaches the southern tip of Sri Lanka and penetrates into the south-eastern Arabian Sea, with values inferior to -0.1 as far north as $12^{\circ} \mathrm{N}$ along the west coast of India in March 1999.

At this point, it is interesting to understand why the SSS difference pattern penetrates in the south-eastern Arabian Sea in 1998-1999 whereas it remains confined to BoB in 1992-1993. One thing is that $1998(\mathrm{G})-(\mathrm{B})$ discharge anomaly is more than twice stronger (in absolute values) than that of 1992 (figure 1). It thus generates a plume of SSS difference of stronger magnitude (e.g., compare the maximal values of -2.85 in September 1998 vs. 0.72 in September 1992; figures 4 and 5). One can expect this stronger pattern to be less prone to dissipation by oceanic mixing, and to survive longer during its subsequent travel in the southward-flowing EICC. In addition, the variability of EICC magnitude may also be able to modulate the export of the freshwater plume through the southern exit of BoB. Figure 6 sheds light on this process. It shows that in November 1992, at the height of southward-flowing seasonal EICC (figure 3), the model exhibits a northward anomaly all along the east coast of Sri Lanka, with typical magnitude of $0.3 \mathrm{~m} \cdot \mathrm{s}^{-1}$. This is of same order of magnitude as the $0.4 \mathrm{~m} \cdot \mathrm{s}^{-1}$ southward seasonal flow, and thus amounts to a virtually idle EICC at this time. In contrast, in November 1998 the model simulates an EICC anomaly of about $0.2 \mathrm{~m} \cdot \mathrm{s}^{-1}$ towards the south along the southeast coast of India, then turning offshore at $7^{\circ} \mathrm{N}$ before bifurcating westward, flowing along $5^{\circ} \mathrm{N}$ past the southern tip of Sri Lanka and into the southern Arabian Sea. This southwestward anomaly interferes constructively with the southwestward seasonal EICC, resulting in a south-westward current of about $0.6 \mathrm{~m} \cdot \mathrm{s}^{-1}$. The mechanism driving these deviations of EICC magnitude around its seasonal climatology is not clear. Nevertheless, the magnitude of these two events appears realistic: along the southeastern coast of Sri Lanka, the altimetry-derived EICC velocity of Durand et al (2009) show an interannual anomaly of $0.11 \mathrm{~m} \cdot \mathrm{s}^{-1}$ towards the northeast in November 1992, and of $0.31 \mathrm{~m} \cdot \mathrm{s}^{-1}$ towards the southwest in November 1998. This results in a more efficient southward transport of the (already stronger) SSS difference pattern along the western boundary in November 1998, as compared to November 1992.

Though figures 4 and 5 illustrate the sequence of events for two particular years, a similar evolution is seen every year of the 1992-1999 period, irrespective of the sign of the anomaly (not shown). Some years, the current anomaly acts to enhance the southward export of SSS anomalies (as in 1998), whereas some other years, it acts against it (as in 1992). Beyond the two particular years we just presented, it is important to quantitatively characterize the spatio-temporal evolution of the pattern of SSS difference between IR and CTRL throughout the 1992-1999 period. BoB SSS variability is forced by river run-off, as well as by ocean-atmosphere freshwater flux and ocean currents. Figure 7 presents the standard deviation (STD) of SSS in CTRL and in IR. Expectedly, the interannual variability of $(\mathrm{G})$ and $(\mathrm{B})$ run-off does not strongly affect the broad spatial patterns of SSS variability: in both CTRL (figure 7a) and IR (figure 7b), SSS variability is strongest in the northern BoB, and weakest in the Arabian Sea. High values of SSS STD (in excess of 0.5 ) stretch in the $\mathrm{BoB}$ from $15^{\circ} \mathrm{N}$ towards the south-west along the east coast of India and Sri Lanka, and then in two opposite directions, towards the west along $5^{\circ} \mathrm{N}$ into the southern Arabian Sea and towards
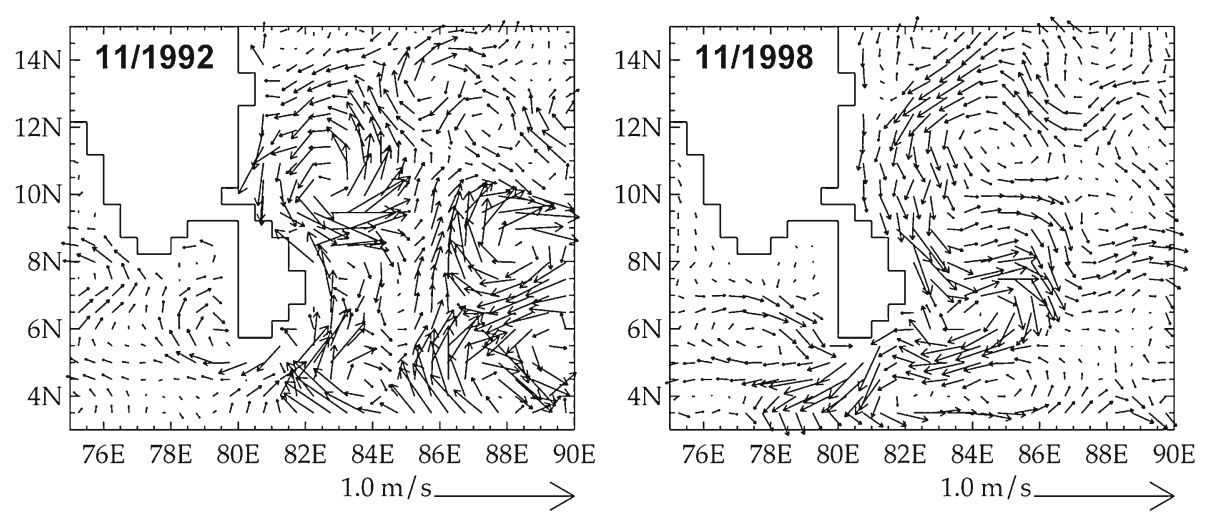

Figure 6. Model surface current anomaly as regards to the long-term mean seasonal climatology in the south-western Bay of Bengal, for November 1992 (left) and for November 1998 (right). 

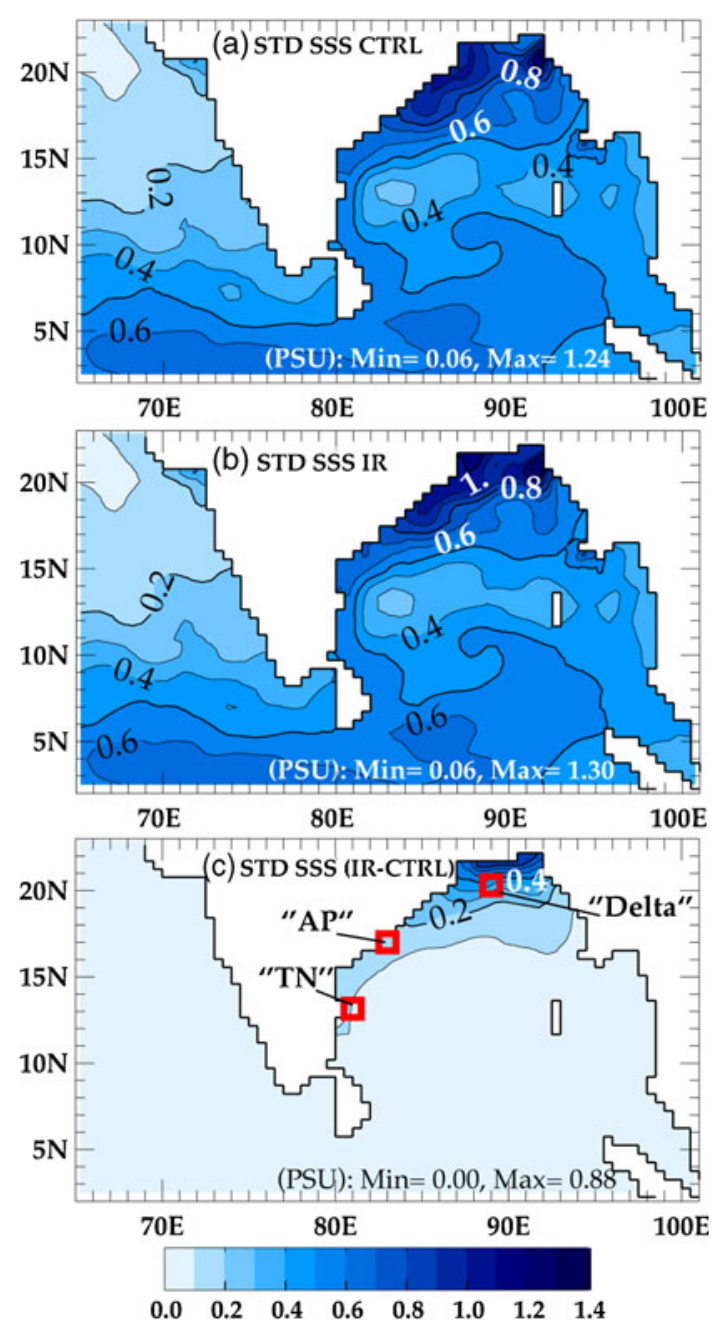

Figure 7. (a) STD of SSS in CTRL run. (b) Same as (a), for IR run. (c) STD of the SSS difference between CTRL and IR. Isocontours are every 0.1. Indicated on each plot are the extreme values. In (c), we show the positions of the three boxes used subsequently: 'Delta' off the GangesBrahmaputra delta, 'AP' off the Indian state of Andhra Pradesh, 'TN' off the Indian state of Tamil Nadu.

the east in the interior BoB. This pattern mimicks the known surface circulation pathways during the post-summer monsoon season, with an equatorward EICC that splits into two branches upon reaching $7^{\circ} \mathrm{N}$, one arm bending westward around the southern tip of Sri Lanka in the Winter Monsoon Current, and one arm turning offshore due east (Vinayachandran et al 2005). A careful examination of CTRL (figure 7a) and IR (figure 7b), however, reveals that IR exhibits slightly higher SSS variability than CTRL north of $15^{\circ} \mathrm{N}$. This is further illustrated by the STD of their difference (figure $7 \mathrm{c}$ ). Consistently with figures 4 and 5 , it is significant (in excess of 0.1 ) in a region situated north of $17^{\circ} \mathrm{N}$ and that stretches along the east coast of India towards the southwest up to about $12^{\circ} \mathrm{N}$. In the northern Bay of Bengal, north of $21^{\circ} \mathrm{N}$, the STD of their difference reaches peak values close to 1 . This is the same order of magnitude as the total variability of SSS itself.

In order to investigate the transport timescales of SSS anomalies from their source region along the EICC pathway, we define three boxes (Delta, AP, TN) located along the tongue of high SSS STD of the difference between CTRL and IR: Delta box $\left(88.5^{\circ}-89.5^{\circ} \mathrm{E}, 19.8^{\circ}-20.8^{\circ} \mathrm{N}\right)$ is situated just offshore the mouth of the river; $\mathrm{TN}$ box $\left(80.5^{\circ}\right.$ $\left.81.5^{\circ} \mathrm{E}, 12.65^{\circ}-13.65^{\circ} \mathrm{N}\right)$ is at the southern edge of the tongue; AP box $\left(82.5^{\circ}-83.5^{\circ} \mathrm{E}, 16.6^{\circ}-17.5^{\circ} \mathrm{N}\right)$ has an intermediate position between the other two (figure 7c). Figure 8 presents the seasonal evolution of SSS root-mean-square-difference (RMSD) between IR and CTRL for the three boxes, along with the seasonal evolution of STD of discharge interannual anomaly. For all boxes, the SSS interannual signal shows a marked seasonality, with peak values during the post-summer monsoon season, subsequent to the peak interannual signal of discharge seen in August. Consistently with what is seen in figure $7(\mathrm{c})$, we note a sharp decrease in the interannual SSS signal from Delta to AP and TN, throughout the year. This is particularly striking during the peak season, with values of $0.8,0.45$ and 0.25 for Delta, AP and TN, respectively. Interestingly, we note a clear time lag between the three boxes in the summer evolution of the interannual salinity signal: while Delta box shows an increase quasi-simultaneous with that of the forcing, beginning in May through late September, it starts in September only in AP box, and in late October in TN box. The timings of peak values are late September, early November and late November, respectively for Delta, AP and TN. This RMSD evolution follows closely the seasonal evolution of the magnitude of SSS anomaly patterns along their pathway from the northern BoB towards the south-west, shown in figures 4 and 5 (and seen on each individual year).

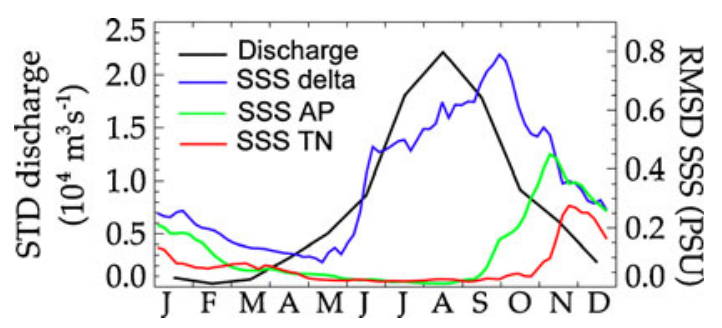

Figure 8. Seasonal evolution of the STD of interannual anomaly of $(\mathrm{G})+(\mathrm{B})$ adjusted discharge (black curve); superimposed are the seasonal evolutions of SSS RMSD between IR and CTRL runs, for 'delta' box (blue), for 'AP' box (green) and for 'TN' box (red) (note the different temporal resolution of 5 days for SSS and of 1 month for discharge). 
Hence our model suggests a characteristic advective timescale of runoff-induced interannual SSS anomalies of about 1 month from $20^{\circ} \mathrm{N}$ to $17^{\circ} \mathrm{N}$ and about 2 months from $20^{\circ} \mathrm{N}$ to $13^{\circ} \mathrm{N}$, along the east coast of India. This is broadly consistent with the typical EICC velocity of about $0.2 \mathrm{~m} \cdot \mathrm{s}^{-1}$ towards the south during the post-monsoon season in the north-western BoB (figure 3).

\section{Impact on Bay of Bengal temperature}

In the previous section, we could see that interannual variability of $(\mathrm{G})-(\mathrm{B})$ discharge exerts a strong influence on upper BoB salinity, with marked signals all along the northern and western periphery of the basin. The heat budget of upper BoB strongly depends on its salinity stratification
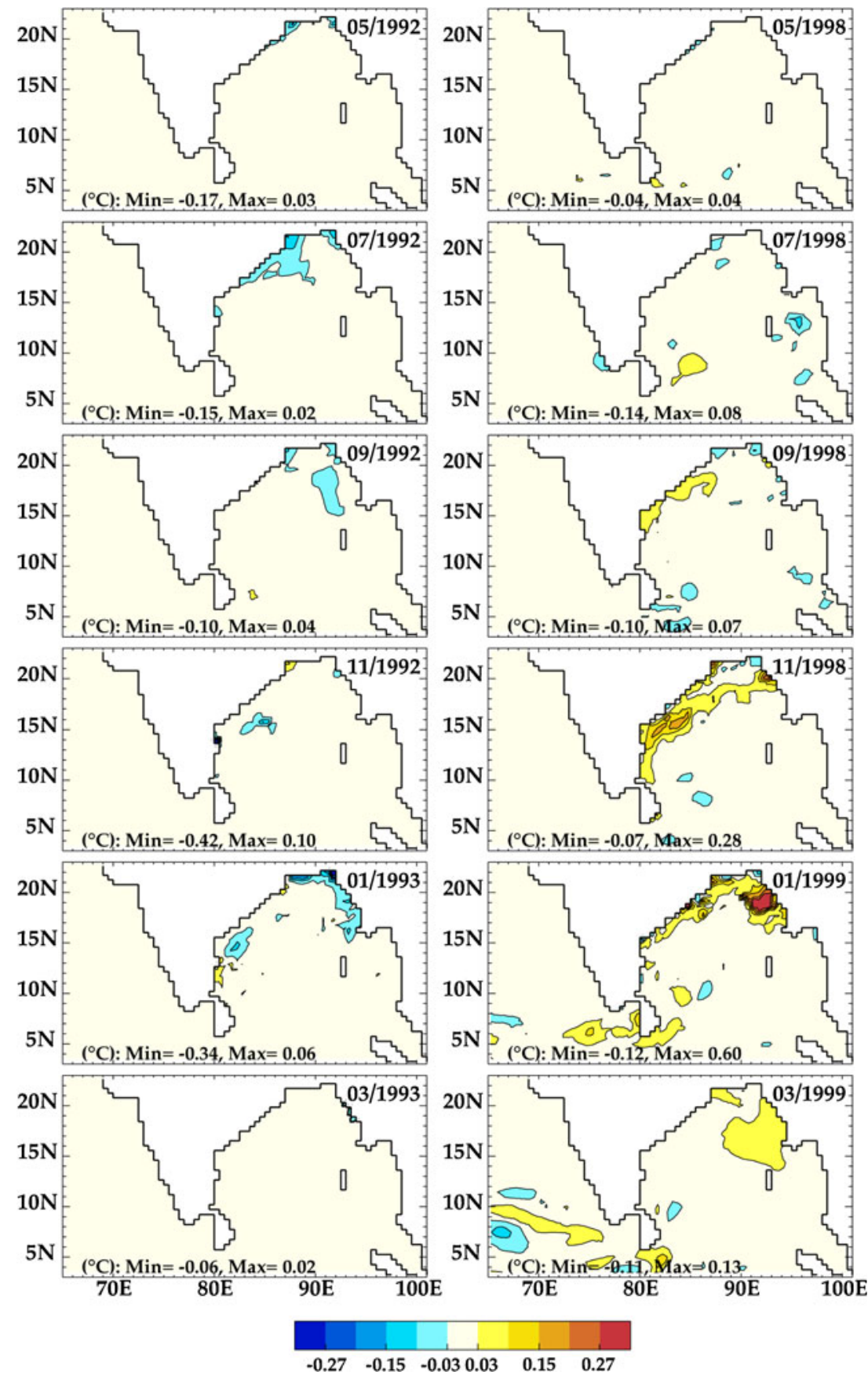

Figure 9. Bi-monthly evolution of difference between IR and CTRL simulations in temperature at $25 \mathrm{~m}$ depth, from May 1992 to March 1993 (left column) and from May 1998 to March 1999 (right column). Each snapshot features monthly averages, the corresponding month being indicated. Also indicated on each difference snapshot are the extreme values plotted. Isolines are every $0.06^{\circ} \mathrm{C}$. 
(Shenoi et al 2002; de Boyer Montégut et al 2007). Thus it appears timely to assess the impact of discharge anomalies on the thermal field of the upper BoB simulated by the model. Figure 9 presents the evolution of temperature difference between IR and CTRL simulations at $25 \mathrm{~m}$ depth, for both 1992-1993 and 1998-1999 anomalous years discussed in previous section. The $25 \mathrm{~m}$ level was chosen after checking that the mixed layer depth simulated by IR does not differ from that of CTRL. As seen in figure 2, it corresponds typically to the bottom of the mixed layer for both runs. We do not discuss here the impact of discharge anomalies on the model SST, despite the fact that it is a more relevant parameter as far as atmospheric dynamics and Asian climate are concerned. The reason is that we are in a forced modelling framework: the model SST is strongly constrained by the bulk formulation used in our heat flux computation, and is not prone to significantly deviate from the NCEP air temperature we prescribe. Figure 9 shows a similar evolution for both events, with thermal anomalies basically confined to the region of largest SSS anomalies. Deficient discharge (in 1992-1993) drives cold anomalies, and excess discharge (in 1998-1999) drives warm anomalies. This can be explained by the active role of salinity on the vertical physics: stronger-than-usual-discharge generates fresher surface waters, which increases the vertical stability of the water column. In turn, this inhibits the downward export of heat from the surface. The heat remains trapped in the upper layers. The reverse process holds for weaker-thanusual discharge. One can see that the cold anomalies generated by the deficient discharge event of 1992-1993 are much weaker than the warm anomalies generated during the excess discharge event of 1998-1999. This can be explained by the weaker SSS signature of 1992-1993 event as compared to 1998-1999. Temperature, however, has no reason to respond linearly to salinity anomalies, given that the vertical physics linking the two is not linear. One limitation of our model has to be highlighted, at this point. The fact that mixed layer depth is not modified in IR as compared to CTRL might be an artifact of our coarse vertical grid. Indeed, in the northern BoB, the mixed layer depth simulated by the model amounts to $20 \mathrm{~m}$ (figure 2). It means that it spans only the first two levels of our model. One would expect that stronger (resp. weaker) runoff would drive a shoaling (resp. thickening) of the MLD. This is not the case in our model, because it is unable to simulate a mixed-layer thinner than $20 \mathrm{~m}$ (except in the extreme regimes just off the mouths of $(\mathrm{G})-(\mathrm{B})$ of Irrawaddy rivers, as seen in figure 2). Thus our model simulates only a part of the buoyancy-driven mechanism explained above (the modification of vertical stability at the bottom of mixed layer, and associated modification of vertical heat exchanges) but misses the other part (the mixed layer depth change). It is seen that the peak temperature anomalies appear in winter (November-January), several months after the peak SSS anomalies. During this season, the upper BoB experiences a broad cooling of about $1^{\circ} \mathrm{C}$, mainly resulting from the forcing exerted by the cold and dry northerly winds. During the 19921993 event, runoff-induced thermal anomaly shows significant patches (in excess of $0.1^{\circ} \mathrm{C}$ in absolute values) of very small extent, confined to the periphery of the Bay. In contrast, one can see a wider area of warm anomaly during 1998-1999, with values in excess of $0.2^{\circ} \mathrm{C}$ in January 1999 over a $2^{\circ} \times 2^{\circ}$ patch centred on $\left(92^{\circ} \mathrm{E}, 19^{\circ} \mathrm{N}\right)$. These values (positive or negative) represent a small, but not negligible fraction of the broad cooling tendency seen during the winter monsoon period.

\section{Discussion on model limitations}

The fact that our model does not exhibit any significant salinity signature of $(\mathrm{G})-(\mathrm{B})$ discharge anomalies south of $10^{\circ} \mathrm{N}$ stands in striking contrast with the inflow of Bay of Bengal low salinity waters in the Equatorial Indian Ocean and in the Arabian Sea inferred from previous observational studies (Shetye et al 1991; Shetye 1993; Shankar and Shetye 1999) as well as from numerical studies in seasonal climatological conditions (Han and McCreary 2001; Jensen 2003; D07). Subsequently to the extreme discharge event of 19981999, however, the model generates SSS anomalies that make their way through the south-western $\mathrm{BoB}$ and into the south-eastern Arabian Sea. This is consistent with the mechanism proposed by Gopalakrishna et al (2005). They suggest that SSS interannual variability in the south-eastern Arabian Sea is driven by interannual variability of $\mathrm{BoB}$ rivers discharge. By comparing two successive years (2002 and 2003), they observe SSS differences of more than 1.0, which is an order of magnitude more than what our model suggests (0.1). Han and Webster (2002) assessed the impact of interannual variability of $(G)-(B)$ run-off on BoB sea level variability in an OGCM. They used a completely different model, with a rather coarse vertical resolution, with a completely different vertical physics from ours, but with the same horizontal resolution of $0.5^{\circ}$. They forced the SSS of their model with a synthetic river run-off product, essentially extrapolated from the variability of continental rainfall over the $(\mathrm{G})-(\mathrm{B})$ watershed, over the period $1958^{-}$ 1998. Their (G)-(B) run-off timeseries exhibits a marked year-to-year variability similar to the one 
seen in the observed timeseries (though of lesser amplitude, amounting to about $50 \%$ of ours). One of their conclusions was that their simulated sea level south of $16^{\circ} \mathrm{N}$ along the western boundary of the BoB is hardly impacted by the interannual variability of the river run-off. This is in line with our own conclusion, and thus points at the horizontal resolution of the model grid as the responsible for the inability of the models to export SSS anomaly patterns through the southern boundary of the BoB. Indeed, besides the good skill of our model to simulate the seasonal cycle of EICC (as seen in section 2), it significantly underestimates the intraseasonal variablility of this current observed in the altimetric data of Durand et al (2009) (not shown). These short timescales are likely to play a role in exporting southward the northern BoB waters along the western boundary. Another drawback of the model circulation is also revealed by the width of the low-salinity tongue transported equatorward by the EICC in the post-monsoon season. In our model, it amounts to several hundreds of $\mathrm{km}$, whereas the observations reported by Shetye (1993) rather suggest a tongue thinner than $100 \mathrm{~km}$ (see his figure 4c). This reveals that the coastal trapping of the equatorward EICC is not properly simulated by our $0.5^{\circ}$ resolution model. This may have strong implications in the capability of this current limb to export the northern BoB freshwater towards the southern BoB and into the Arabian Sea. We found that the SSS anomaly patterns hardly survive more than one season in the BoB. The reasons for the short memory of the model mixed layer are two-fold. One thing is that the vertical physics acts to erode the surface-trapped SSS difference. Indeed, using the same version of the model (with only slightly different forcing strategy), de Boyer Montégut (2005) concluded that vertical mixing is the only significant factor of upper BoB saltening throughout the year (see his figure 46). He found that the vertical input of subsurface salty water within the mixed layer reaches its maximum during the post-monsoon season (September-December), precisely when our runoffdriven SSS anomalies build up and disappear. The realism of this process is difficult to assess with the available observations and needs to be checked with models using a different vertical physics and/or a higher vertical resolution. The relatively coarse horizontal resolution of our model may also favour a short memory of the model mixed layer. This stems from the way the model physics represents the turbulence. The $(\mathrm{G})-(\mathrm{B})$ outlet is of small horizontal scale as compared to the size of the basin, and thus generates SSS anomaly patterns of small extent, bounded by strong gradients (see the pictures for August in figures 4 and $5)$. The EICC stretches the SSS anomaly patterns in the alongshore direction (see e.g., the pictures for November in figures 4 and 5), hereby preserving the magnitude of the gradients in the cross-shore direction. The mesoscale activity of the ocean is not explicitly resolved by our $0.5^{\circ}$ grid; it is instead simply parameterized in the model by a strong horizontal diffusion operator. This is done classically in all OGCMs of this class, at this resolution. The diffusion acts to damp and dilute the coastallytrapped SSS patterns in the offshore direction, all along the western boundary, as the post-monsoon season advances. In contrast, an eddy-resolving model would probably retain the imprint of this anomalies during a longer time, under the form of mesoscale eddies and sub-mesoscale filaments.

\section{Concluding remarks}

In this paper, we investigate the impact of monthly Ganges-Brahmaputra river discharge variations on Bay of Bengal salinity and temperature during the period 1992-1999. First, we present the Ganges and Brahmaputra river discharges, based on a multi-year in situ dataset. Both rivers exhibit a clear seasonal cycle, with high flow during and after summer monsoon, and low flow in winter-spring. Superimposed on this well-known seasonal cycle, the discharge of both rivers shows a marked interannual variability, corresponding to a modulation of the magnitude and timing of the monsoonal peak. Over the 1992-1999 period, all interannual anomalies of the combined $(\mathrm{G})-(\mathrm{B})$ discharges last less than a year.

Expectedly, the impact of these interannual discharge anomalies on the SSS simulated by our OGCM is strongest in the northern Bay of Bengal. Most of the time, the impact of interannual variability of the Ganges-Brahmaputra discharge on SSS does not extend south of $10^{\circ} \mathrm{N}$, which stands in contradiction with the available in situ observations and points at the horizontal resolution of the current generation of $\mathrm{BoB}$ circulation models as a limitation.

Another major result of our study concerns the impact of interannual (G)-(B) discharge anomalies on the upper ocean temperature. It is found to be strong in the north-eastern $\mathrm{BoB}$, with values of order $0.2^{\circ} \mathrm{C}$ at $25 \mathrm{~m}$ depth subsequently to the 1998 discharge event. This result may have implications in the dynamics of the ocean-atmosphere coupled system. This region, indeed, corresponds to the region of both maximal precipitation and maximal intraseasonal variability of the precipitation (Hoyos and Webster 2007). This conclusion needs to be checked in a modelling framework with sufficient vertical resolution to adequately resolve 
the very thin mixed layers (of order or less than $20 \mathrm{~m}$ ) ubiquitous in the northern BoB.

From our diagnostics, it appears compulsory to use a higher resolution model to quantitatively investigate the upper Bay of Bengal salinity structure. Typically a model actually capable of resolving explicitly the ocean flow at the scale of one Rossby radius (of order $60 \mathrm{~km}$ in the $\mathrm{BoB}$ ) is required. This would allow to curb the three main drawbacks of a $0.5^{\circ}$ model, which are an underestimation of the high-frequency variability of the EICC, an overestimation of the width of this current vein, and a simplistic representation of the horizontal turbulence. These three problems all have an impact on the BoB salinity patterns simulated.

With the advent of ARGO program after 2002 and the launch of SMOS satellite in November 2009, the salinity observing system in the BoB is developing tremendously. When discharge data become available for the recent years it will also be timely to validate the conclusions inferred from numerical modelling.

\section{Acknowledgements}

This study was funded by IRD, CNES and a NASA's NEWS Grant NNDX7AO90E managed by Dr Jared K Entin. We are indebted to the people who collected in situ hydrological observations. The OGCM experiments were carried out on an IBM P5-575 at CNES-Toulouse, France. Support from this institution is gratefully acknowledged. We thank Peter Webster, Gaël Alory, Gurvan Madec and William Rossow for their constructive comments. D Shankar and two anonymous reviewers gave useful advices that helped us improve the quality of the manuscript.

\section{References}

Bentamy A, Quilfen Y, Gohin F, Grima N, Lenaour M and Servain J 1996 Determination and validation of average wind fields from ERS-1 scatterometer measurements; Global Atmos. Ocean Syst. 4 1-29.

Blanke B and Delecluse P 1993 Variability of the tropical Atlantic Ocean simulated by a general circulation model with two different mixed layer physics; J. Phys. Oceanogr. 23 1363-1388.

Chowdhury M R and Ward N 2004 Hydro-meteorological variability in the Greater Ganges-BrahmaputraMeghna Basins; Int. J. Climatol. 24 1495-1508, doi: 10.1002/joc. 1076 .

Dai A and Trenberth K E 2002 Estimates of freshwater discharge from continents: Latitudinal and seasonal variations; J. Hydrometeorol. 3 660-687.

Dai A, Qian T and Trenberth K E 2009 Changes in continental freshwater discharge from 1948 to 2004 , J. Climate 22(10) 2773-2792, doi: 10.1175/2008JCLI2592.1. de Boyer Montégut C, Madec G, Fischer A S, Lazar A and Iudicone D 2004 Mixed layer depth over the global ocean: An examination of profile data and a profilebased climatology; J. Geophys. Res. 109 C12003, doi: 10.1029/2004JC002378.

de Boyer Montégut C 2005 Couche mélangée océanique et bilan thermohalin de surface dans l'Océan Indien Nord; PhD thesis, University of Paris VI, 181 pp. Available on tel.archives-ouvertes.fr/docs/00/05/58/75/ PDF/these_clem_pdf_edition_20051025.pdf.

de Boyer Montégut C, Vialard J, Shenoi S S C, Shankar D, Durand F, Ethé C and Madec G 2007 Simulated seasonal and interannual variability of mixed layer heat budget in the northern Indian Ocean; J. Climate 20 3249-3268.

Delcroix T, Dessier A, Gouriou Y and McPhaden M 2005 Time and space scales for sea surface salinity in the tropical oceans; Deep-Sea Res. 52 787-813.

Durand F, Shankar D, de Boyer Montégut C, Shenoi S S C, Blanke B and Madec G 2007 Modeling the barrier-layer formation in the south-eastern Arabian Sea; J. Climate 20 2109-2120, doi: 10.1175/JCLI4112.1.

Durand F, Shankar D, Birol F and Shenoi S S C 2009 Spatiotemporal structure of the East India Coastal Current from satellite altimetry; J. Geophys. Res. 114 C02013, doi: 10.1029/2008JC004807.

Fekete B M, Vorosmarty C J and Grabs W 2000 Global, composite runoff fields based on observed river discharge and simulated water balances; Documentation for UNHGRDC Composite Runoff Fields, v.1.0, Global Runoff Data Center, Koblenz, Germany.

Gadgil S, Joseph P V and Joshi N V 1984 Ocean-atmopshere coupling over monsoon regions; Nature 312 141-143.

Gopalakrishna V V, Johnson Z, Salgaonkar G, Nisha K, Rajan C K and Rao R R 2005 Observed variability of sea surface salinity and thermal inversions in the Lakshadweep Sea during contrast monsoons; Geophys. Res. Lett. 32 L18605, doi: 10.1029/2005GL023280.

Han W and McCreary J P 2001 Modeling salinity distributions in the Indian Ocean; J. Geophys. Res. 106 859-877.

Han W and Webster P J 2002 Forcing mechanisms of sea level interannual variability in the Bay of Bengal; J. Phys. Oceanogr. 32 216-239.

Hoyos C D and Webster P J 2007 The role of intraseasonal variability in the nature of Asian monsoon precipitation; J. Climate 20 4402-4424.

Jensen T G 2003 Cross-equatorial pathways of salt and tracers from the northern Indian Ocean: Modelling results; Deep-Sea Res. II 50 2111-2127.

Jian J, Webster P J and Hoyos C D 2009 Large-scale controls on Ganges and Brahmaputra river discharge on intraseasonal and seasonal time-scales; Quart J. Roy. Meteorol. Soc. 135 353-370, doi: 10.1002/qj.384.

Kalnay E and Coauthors 1996 The NCEP/NCAR 40Year Reanalysis Project; Bull. Amer. Meteor. Soc. 77 437-471.

Levitus S 1998 Climatological Atlas of the World Ocean; NOAA Prof. Paper 13, 173 pp. and 17 microfiche.

Madec G 2008 NEMO reference manual, ocean dynamics component, Note du pôle de modélisation, IPSL, France $\mathrm{N}^{\circ} 27$ ISSN $\mathrm{N}^{\circ} 1288-1619$.

Mariano A J, Ryan E H, Perkins B D and Smithers S 1995 The Mariano Global Surface Velocity Analysis 1.0; Rep. CG-D-34-95, 55 pp., U.S. Coast Guard, Washington, D. C.

Papa F, Durand F, Rahman A, Bala S K and Rossow W B 2010 Satellite altimeter-derived monthly discharge of the Ganga-Brahmaputra River and its seasonal to 
interannual variations from 1993 to 2008; J. Geophys. Res. 115 C12013, doi: 10.1029/2009JC006075.

Sengupta D, Bharath Raj G N and Shenoi S S C 2006 Surface freshwater from Bay of Bengal runoff and Indonesian throughflow in the tropical Indian Ocean; Geophys. Res. Lett. 33 L22609, doi: 10.1029/2006GL027573.

Shankar D and Shetye S R 1999 Are interdecadal sea level changes along the Indian coast influenced by variability of monsoon rainfall? J. Geophys. Res. 104(C11) 26,03126,042 .

Shankar D, Vinayachandran P N and Unnikrishnan A S 2002 The monsoon currents in the north Indian Ocean; Progr. Oceanogr. 52 63-120.

Shenoi S S C, Shankar D and Shetye S R 2002 Differences in heat budgets of the near-surface Arabian Sea and Bay of Bengal: Implications for the summer monsoon; J. Geophys. Res. 107 3052, doi: 10.1029/2000JC000679.

Shetye S R 1993 The movement and implications of the Ganges-Bramhaputra runoff on entering the Bay of Bengal; Curr. Sci. 64(1) 32-38.

Shetye S R, Shenoi S S C, Gouveia A D, Michael G S, Sundar and Nampoothiri G 1991 Wind-driven coastal upwelling along the western boundary of the Bay of Bengal during the southwest monsoon; Cont. Shelf Res. 11 1397-1408.

Shetye S R, Gouveia A D, Shankar D, Shenoi S S C, Vinayachandran P N, Sundar D, Michael G S and Nampoothiri G 1996 Hydrography and circulation in the western Bay of Bengal during the northeast monsoon; J. Geophys. Res. 101 14,011-14,025, doi: 10.1029/95JC03307.

Vinayachandran P N, Murty V S N and Ramesh Babu V 2002 Observations of barrier layer formation in the Bay of Bengal during summer monsoon; J. Geophys. Res. 107(C12) 8018, doi: 10.1029/2001JC000831.

Vinayachandran P N, Kagimoto T, Masumoto Y, Chauhan P, Nayak S R and Yamagata T 2005 Bifurcation of the East India Coastal Current east of Sri Lanka; Geophys. Res. Lett. 32 L15606, doi: 10.1029/2005GL022864.

Vinayachandran P N and Nanjundiah R S 2009 Indian Ocean sea surface salinity variations in a coupled model; Clim Dyn., doi: 10.1007/s00382-008-0511-6.

Xie P and Arkin P 1997 Analyses of global monthly precipitation using gauge observations, satellite estimates, and numerical model predictions; J. Climate $\mathbf{9}$ $840-858$. 